\title{
Wellbeing of a selection of seafarers in Eastern Adriatic Sea during the COVID-19 pandemic 2020
}

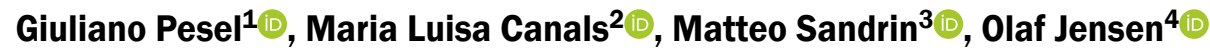 \\ ${ }^{1}$ Policlinico Triestino SPA, Italy \\ ${ }^{2}$ Sociedad Española de Medicina Marítima (SEMM)/University of Cadiz FUECA, Spain \\ ${ }^{3}$ Adriatic Nautical Academy of Trieste, Safety and Security Maritime Advisor, Italy \\ ${ }^{4}$ Centre of Maritime Health and Society, Department of Public Health, University of Southern Denmark, Esbjerg, Denmark
}

\begin{abstract}
Background: Work-related stress among seafarers is well known but a suspected excess of work-related stress due to the COVID-19 so far has not been published. The aim of the study was to evaluate the well-being of the seafarers during the outbreak of COVID-19 pandemic and their evaluation of the precautions taken by the shipping companies.

Materials and methods: Seventy-two seafarers completed the General Health Questionnaire (GHQ12) with three extra questions on how the COVID-19 precautions were taken on board.

Results: The mean Likert score was 13.9 for the whole sample, corresponding to "no problems" while a subgroup of $40 \%$ had mean Likert sum scores of 16.1 (level 15-23) corresponding to "starting problems." In response to the extra items, $50 \%$ of the seafarers did not feel safe doing their job in relation to the epidemic and $60 \%$ did not think everything has been done to ensure their health at work in relation to the epidemic. Thirty per cent suffered of insomnia to the extent of becoming concerned and $26 \%$ had been unhappy and depressed during the latest tours of duty.

Conclusions: The hypothesis that excess work-related stress has been put on the seafarers in this specific situation was confirmed and calls for prevention. A combination of person-focused and organisation-focused prevention approaches has been advocated as the most promising for alleviation of job stress in the workplaces at sea.
\end{abstract}

(Int Marit Health 2020; 71, 3: 184-190)

Key words: seafarers, wellbeing, pandemic, work related stress

\section{INTRODUCTION}

Many people worldwide and especially in the countries of southern Europe (e.g. Italy and Spain) have been severely affected by the COVID-19 pandemic. The situation is causing many risks and problems even for workers who have to continue working during the epidemic, such as seafarers.

Seafarers often experience stress connected with their specific work conditions, job responsibility and psychosocial factors, which generate health and psychological problems [1-3]. As the problem mainly affects the population on land, seafarers are expected to feel very safe in ships, but the preliminary results of this study seem to pose instead for a considerable sense of concern for their health in the group of seafarers. During the latest months there has been high attention to the COVID-19 from International Maritime Organisation/International Labour Organisation (IMO/ILO) but there is so far no scientific studies published.

The objective was to investigate in time the impact of the pandemic on the physical and mental well-being of seafarers, considering the situation as a risk factor due to excess work-related stress due to the pandemic. We also want to investigate the level of satisfaction of workers regarding the measures implemented in ships and ports and their 
subjective perception of risk and safety in this moment. The hypothesis is that that excess work-related stress has been put on the seafarers in this specific situation. Our study is part of a context where the difficulty of detecting and measuring psychological problems that can be exacerbated by related stress on work is ascertained.

\section{MATERIALS AND METHODS}

A cross-sectional study design by the use of a standard questionnaire with a random sampling method of the seafarers and the type of ships was used. All seafarers passing through the terminal from the ships were asked to complete the questionnaire on a Tablet/iPhone or answer the interviewer who entered the data in the Tablet. The container ships involved in the study make weekly calls in the Port of Trieste. One of the authors delivered the questionnaire to the seafarers in a hit and returned the completed document to the next hit in Trieste.

The questionnaires were administered on a voluntary basis to all ranks of seafarers from a sample of the container ships of all sizes ( 5 ships with different flags) arriving to Trieste Container Terminal in the 4 months period from January to April 2020.

The variables include personal data, ship type, position on board, workplace and the 12-item General Health Questionnaire and three more questions on the correct handling of the prevention in COVID-19 by the company.

The study size was based on a decision to stop the data collection when 50 questionnaires have returned; howev$\mathrm{er}$, due to unexpected quick completing there was time to extend 72 participants. The analysis was done in SPSS v.26. Each of the Goldberg's General Health Questionnaire (GHQ12) items has four answer options: 1) more than usual, 2) as usual, 3) less than usual, and 4) much less than usual describing mood states. Using the Likert code method 0-1-2-3 gives a total score range of 0-36.

The Likert sum scores were classified as $0-14$ (no problems), 15-19 (starting problems) and 19-36 (serious problems). Analyses of the Likert scores were divided in two groups: group 1: Likert score 0-14 no problems, (no action needed) and group 2: Likert score 15-19 starting problems (included 2 with Likert score 20-36: serious problem).

Stratification was done of the variables: age $<40$ and $>40$ years of age, officer/non-officer, workplace: bridge, kitchen, deck and engine and nationality in four groups and on Likert sum scores, no problems $(0-14)$ and problems (15-19). Cross-tab analysis was done for the question: "Do you think everything has been done to ensure your health at work in relation to the COVID-19 pandemic?" and the responders with Likert score 15-19 "Less than usual". See Table 1 for the complete questionnaire.

\section{RESULTS}

\section{STUDY POPULATION}

A total 72 consecutive seafarers, all men, entered the study. All invited seafarers were willing to participate and there were no missing values in the completion of the questionnaires. The age distribution was as follows: 15 - 39 years, $n=32(44 \%), 40-60$ years, $n=40$ ( $56 \%$ ). Mean age $39 \pm 11.2$ years, range $11-60$, median 41 . Non-officers, $n=41$ (57\%). Officers, $n=31(43 \%)$. Working department on ship: bridge, $n=4(6 \%)$, galley, $n=8(11 \%)$, deck, $n=36(50 \%)$, engine, $n=24$ (33\%). Nationality of seafarers was as follows: Asian countries, $n=39(54 \%)$. European countries, $n=12(17 \%)$. Russian and former Soviet Union (USSR) countries, $n=20(28 \%)$ and other countries, $n=1(1.3 \%)$.

\section{LIKERT SCORE DISTRIBUTIONS}

Frequency distribution of GHQ12 scores for the total sample (Table 2). Distribution of the Likert sum scores: 0-14 (no problems; $n=43 ; 59.7 \%$ ), 15-19 (starting problems; $n=28 ; 38.9 \%$ ) and $19-36$ (serious problems; $n=2$; 1.3\%). The mean Likert score was 13.9 (sum $=1004 / 72$ ). Distribution of the Likert scores level 15-19: "Less than usual" were as follows: officers $n=31$ (45.2\%) and non-officers, $n=41(36.6 \%)$. In relation to the workplace on board the engine room personnel with $n=24(50 \%)$ ranged highest and the Russian and the Asian seafarers with scores on $45 \%$ and $38.5 \%$, respectively ranged highest among the nationalities (Table 3).

\section{LIKERT SCORE 2-3 TO THE SPECIFIC ITEMS}

Figure 1 describes the personal prevalences of the two levels Likert score $0-1=$ "same as usual" and 2-3 $=$ "less than usual or worse" to each of the 12 items. The highest prevalence for $47 \%$ of the participants marked Likert score 2-3 means that $47 \%$ of all felt "less than usual happy emotionally" and $40 \%$ marked Likert score 2-3 "less than usual been able to carve out free time for yourself and enjoy it".

\section{THE EXTRA QUESTIONS ADDED TO THE GHQ12}

Sixty-three per cent of the non-officers and $55 \%$ of the officers did not think "that everything has been done to ensure their health at work in relation to the COVID-19 pandemic" (Fig. 2).

Fifty-four per cent of the non-officers and $52 \%$ of the officers did not feel safe doing their job in relation to the epidemic. And $73 \%$ of the non-officers and $74 \%$ of the officers did think "that the international situation has relatively changed the responses of this test compared to before the crisis". 
Table 1. All questions of questionnaire

Psycho-physical wellbeing and risk of work related stress in SEAFARERS in a situation of international emergency situation due to COVID-19 epidemic in 2020. A brief investigation using the GENERAL HEALTH QUESTIONNAIRE (GHQ12)

Age of Seafarer:

Nationality of Seafarer: $\quad \square$ European Countries (all)

$\square$ Russian and ex URSS Countries

$\square$ Asian Countries

$\square$ North-African, Middle East and Arabic Countries

$\square$ African Countries

$\square$ Others Countries

\section{Please ask to all the following questions sincerely (GHQ12 questionnaire)}

\begin{tabular}{|c|c|c|c|c|}
\hline In the last 2 weeks you have: & $\begin{array}{l}\text { More than } \\
\text { usual }\end{array}$ & $\begin{array}{l}\text { Same as } \\
\text { always }\end{array}$ & $\begin{array}{l}\text { Less than } \\
\text { usual }\end{array}$ & $\begin{array}{l}\text { Much worse } \\
\text { than usual }\end{array}$ \\
\hline $\begin{array}{l}\text { 1. Been able to concentrate on what one is doing? } \\
\text { Eg. Can follow the point of a discussion. can concentrate } \\
\text { while reading, etc. }\end{array}$ & 0 & 1 & 2 & 3 \\
\hline 2. Suffered insomnia to extent of becoming concerned? & 3 & 2 & 1 & 0 \\
\hline $\begin{array}{l}\text { 3. Been productive (doing lots of things) in most of the } \\
\text { activities undertaken? }\end{array}$ & 0 & 1 & 2 & 3 \\
\hline 4. Been able to make decisions in moat cases? & 0 & 1 & 2 & 3 \\
\hline 5. Been constantly under pressure? & 3 & 2 & 1 & 0 \\
\hline 6. Not he able to overcome difficulties? & 3 & 2 & 1 & 0 \\
\hline 7. Been able to carve out free time for yourself and enjoy it? & 0 & 1 & 2 & 3 \\
\hline 8. Been able to resolve your problems? & 0 & 1 & 2 & 3 \\
\hline 9. Been unhappy and depressed? & 3 & 2 & 1 & 0 \\
\hline 10.Felt as if you have lost faith in yourself? & 3 & 2 & 1 & 0 \\
\hline 11.Felt as if you have less self-esteem? & 0 & 1 & 2 & 3 \\
\hline 12.In general felt a happy emotional state of mind? & 0 & 1 & 2 & 3 \\
\hline
\end{tabular}

Do you think that the international situation has relatively changed the responses of this test compared to before the crisis?

$$
\square \text { Yes } \square \text { No }
$$

Do you think everything has been done to ensure your health at work in relation to the COVID epidemic?

$$
\square \text { Yes } \quad \square \text { No }
$$

Do you feel safe doing your in relation to the epidemic?

$$
\square \text { Yes } \quad \square \text { No }
$$

Your rank: $\quad \square$ No officer (crew)

$$
\square \text { Officer }
$$

Your job: $\quad \square$ Deck

$$
\begin{aligned}
& \square \text { Engine-Engineer } \\
& \square \text { Steward } \\
& \square \text { Other job }
\end{aligned}
$$

Thank you for your kind collaboration! We want to improve the health and life of seafarers. The questionnaire is anonymous and will be treated in compliance with the privacy legislation (GDPR).

The data is used for research purposes. Thank you for your kind collaboration.

Giuliano Pesel, MD, Occupational Medicine. Ord. Med. N. 3988 Trieste

Corso de Especialista en medicina del trabajo maritimo. Course for specialist in occupational maritime medicine - Fundación Universidad Empresa de la provincia de Cádiz, Spain.

\section{DISCUSSION}

This is to our knowledge the first study to investigate the impact of the COVID-19 pandemic on seafarers' mental and physical risk factors during their stay and work on board. Seventy-two seafarers from container ships of different sizes and from different countries completed the GHQ12 and three extra questions on how the COVID-19 precautions were taken on board by the companies. The mean Likert score was 13.9 for all, which corresponds to the cut-off limit for "no problems". However, by stratification of the Likert 
score levels, then $40 \%$ of the sample was in the range of 15-19 Likert score indicating "starting problems". Further, in the response of the three extra items, $50 \%$ of the sample did not feel safe doing their job in relation to the epidemic and $60 \%$ did not think everything has been done to ensure their health at work in relation to the epidemic (Fig. 2).

The hypothesis that excess work-related stress has been put on the seafarers in this specific situation was confirmed with a need to take specific preventive precautions for all of them.

A combination of elevated Likert score on the level of "starting problems" and that more than $50 \%$ of all did not feel safe about the precautions done by the shipping company in the actual situation indicates an urgent need to establish a care-taking programme for the seafarers

Table 2. Frequency distribution of Likert GHQ12 scores for all $(\mathrm{n}=72)$

\begin{tabular}{lcc}
\hline Score & Number & Per cent \\
\hline 10 & 1 & $1.3 \%$ \\
11 & 10 & $14 \%$ \\
12 & 15 & $21 \%$ \\
13 & 7 & $10 \%$ \\
14 & 10 & $14 \%$ \\
15 & 11 & $15 \%$ \\
16 & 12 & $17 \%$ \\
17 & 3 & $4 \%$ \\
18 & 2 & $2.6 \%$ \\
23 & 1 & $1.3 \%$ \\
Total & 72 & $100 \%$
\end{tabular}

on the personal level and the organisational level in the companies. A combination of person-focused and organisation-focused approaches has been advocated as the most promising for alleviation of job stress in the workplaces at sea $[4,5]$. That $60 \%$ of the whole sample had Likert sum scores 0-14 (cut-off level "no problems") does not mean, that this group is free of any problems, but that they probably has higher personal resilience and so the need for organisational preventive programme is as important for them as for those with the highest Likert scores. For comparison, a study with 350 seafarers in international shipping, higher levels of resilience, longer seafaring experience and greater work support were significantly associated with lower levels of self-reported stress at sea [6].

\section{METHODS}

The most popular questionnaire for measuring general well-being and the risk of mental illness is probably Goldberg's General Health Questionnaire. This tool assesses well-being by detecting the possible presence of symptoms that could be the result of a stress condition, and offers a rapidly variable measure over time, such as to be valid in periodic monitoring of the state of health. In alternative to the classic version with 60 items, we used the shorter version with 12 items, the GHQ12, expecting this to give a better response rate than using the longer version. About $80 \%$ of the questionnaires were administered faceto-face, the rest were filled in by the seafarers on board and subsequently delivered. With regard to the questions in the questionnaire, a shorter and easier to understand version was chosen that best suits our purpose than the Goldberg format.

Table 3. Distribution of Likert score 15-21: "Less than usual" in the demographic groups $(n=28 / 72)$ *

\begin{tabular}{|c|c|c|c|c|}
\hline & Likert score 15-21 & Whole sample & Per cent & $95 \% \mathrm{Cl}$ \\
\hline \multicolumn{5}{|l|}{ Rank } \\
\hline Officers & 13 & 31 & 45.2 & $28-62$ \\
\hline Non-officers & 15 & 41 & 36.6 & $23-52$ \\
\hline Work place on board & & 72 & & \\
\hline Deck & 14 & 36 & 38.9 & $24-55$ \\
\hline Engine & 12 & 24 & 50.0 & $31-69$ \\
\hline Galley & 1 & 8 & 12.5 & $1-48$ \\
\hline Bridge & 1 & 4 & 25.0 & $1-76$ \\
\hline \multicolumn{5}{|l|}{ Nationality } \\
\hline Asian countries & 15 & 39 & 38.5 & $24-54$ \\
\hline Russian and ex USSR countries & 9 & 20 & 45.0 & $25-67$ \\
\hline European countries & 4 & 12 & 33.3 & $12-62$ \\
\hline Other countries & 0 & 1 & 0.0 & $0-0$ \\
\hline
\end{tabular}




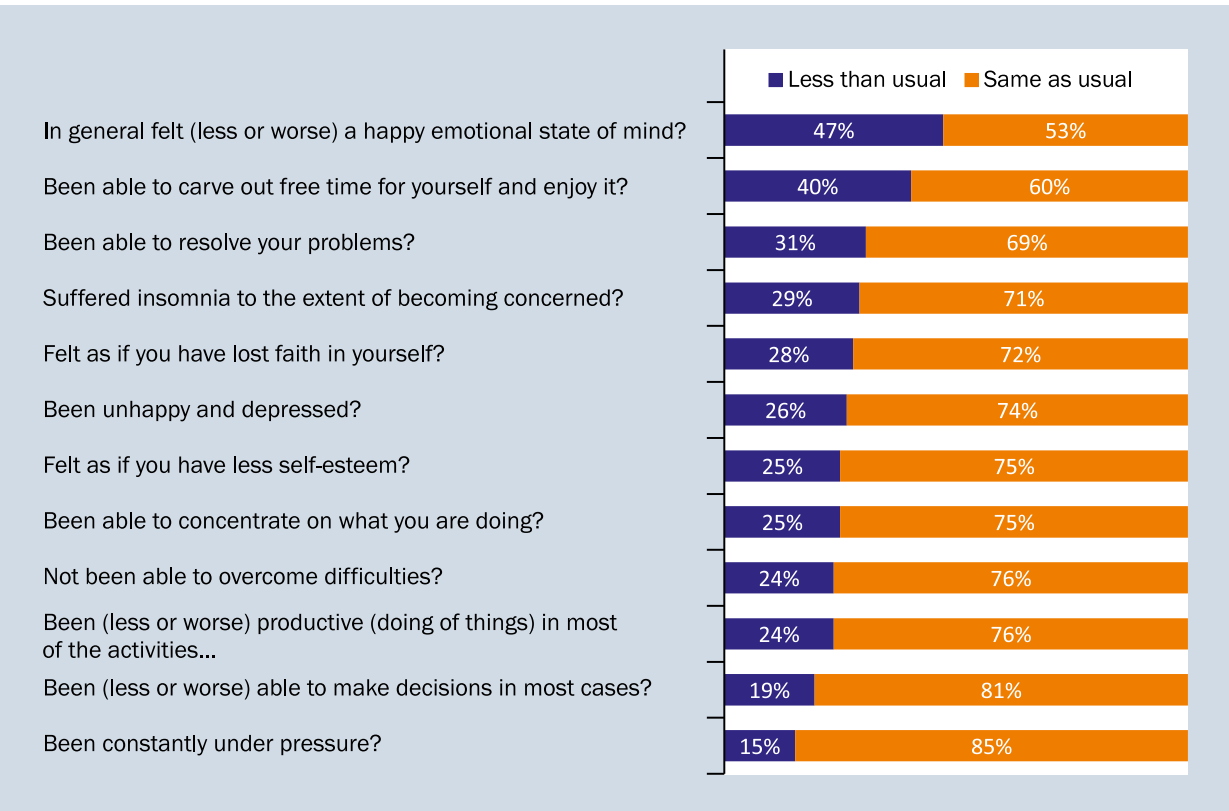

Figure 1. Distribution of prevalence of Likert score 0-1 = "same as usual" and 2-3 = "less than usual or worse" to each of the 12 items the GHQ12 $(n=72$ ). Explanation: as an example, in the upper row $47 \%$ marked blue with a Likert score $2-3$ means that $47 \%$ of all felt "less than usual happy emotionally" and 53\% marked orange had Likert score 0-1 felt "same as usual"

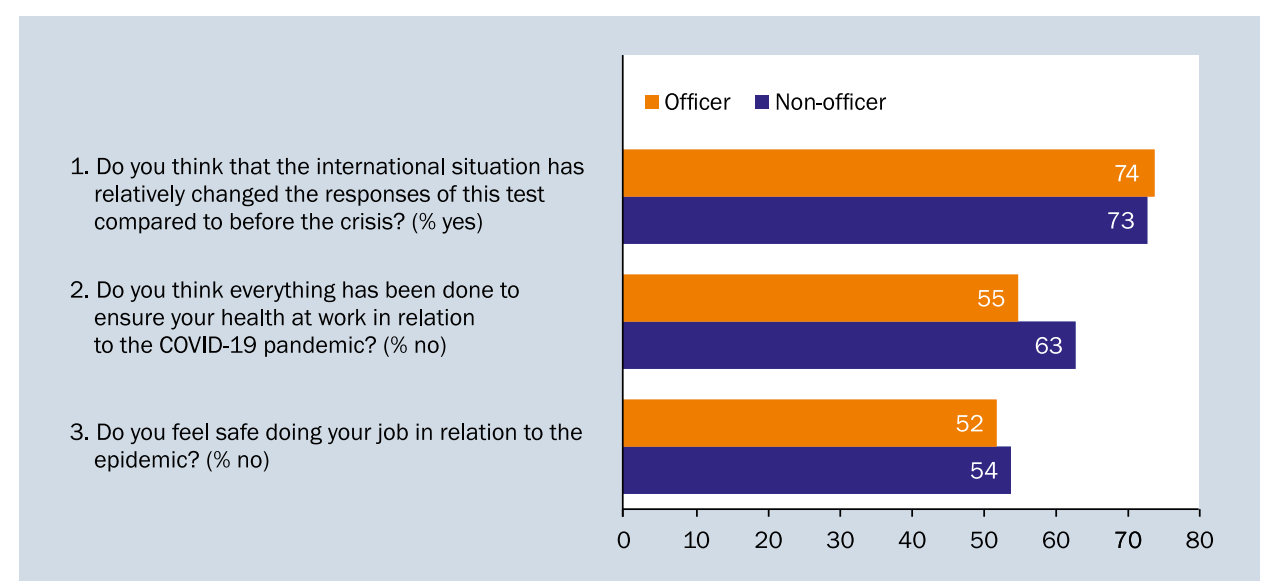

Figure 2. Percentages of officers $(n=31)$ and non-officers $(n=41)$ who answered "Yes" to question 1 and "No" to question 2-3

\section{GHQ12 LIKERT SCORES}

The overall distribution of Likert sum scores were: 0-14 (no problems, $n=43 ; 59.7 \%$ ), score $15-19$ (starting problems, $n=28 ; 38.9 \%$ ) and $19-36$ (serious problems, $\mathrm{n}=2 ; 2.3 \%$ ). The sum of Likert scores among the 72 participants $=1004$ corresponding to a mean of 13.9 Likert scores corresponding to a cut-off limit for "starting problems", $n=28 ; 38.9 \%$. In comparison with the studies by Sampson et al. [7] these levels are somewhat similar to the presence of a 'psychiatric disorder' of 37\% in 2016 that had risen substantially from $28 \%$ in 2011 ( $p=0.000$ ), Martin et al. [8] found by comparison with other scoring methods that the GHQ12 is a reliable screening instrument for psychological distress in clinical groups. Lundin et al. [9] found sufficient sensitivity and specificity by the use of the GHQ12 for separating those with or without a depressive disorder was reached at $\geq 12$ Likert scored points. Winefield et al., 2003 [10] found GHQ12 Likert score mean values of 11.6-14.00 among university staff. The academics scored generally higher than general staff and teaching and research staff scored highest. All questions related to the GHQ test were weighed according to Likert. The results of the final questions on the subjective perception of stress were calculated separately. 


\section{STRENGTH AND WEAKNESS OF THE STUDY}

The instructions of the questionnaire invite the subjects to choose the answer that "seems more correct", that is, to subjectively estimate their degree of agreement about the question asked. This tool offers a rapid and focused measure of a person's general well-being, both physically and psychologically. The problem of evaluation by means of questionnaires is always linked to the subjectivity of the answers provided by the interviewees. The small study size ( $n=72$ ) is prone to wider statistical confidence intervals from which no firm conclusions can be drawn and does not allow for age-group, job-function/work area. Further, when $73 \%$ of the non-officers and $74 \%$ of the officers did think "that the international situation has relatively changed the responses of this test compared to before the crisis", then the results are probably influenced in a direction with worse results than before the crisis. A further limitation of the study could be related to the fact that some questionnaires were not completed face-to-face, as explained in the methods. Stratification results below $n=10$ require a critical note and in general conclusions should be drawn with reserve. It is possible that there was some misunderstanding or boycott of the questionnaire by some interviewees. A barrier to the analysis of seafarers' depression and other psychological problems caused or aggravated by work related stress comes from the lack of information on the characteristics of the seafaring population. The Global Seafarer noted that in the 1980s there was a dramatic change in recruitment strategies for seafarers with an increasing proportion of seafarers being hired from developing countries and East Asia, particularly the Philippines, and this represents a selection bias [11].

\section{FUTURE STUDIES}

The bio-markers such as the salivary alpha-amylase measurements have emerged as valid and reliable objective marker of work related stress [12]. A biological marker could be the solution for an objective evaluation, considering the difficulties and uncertainty, found in the literature, in evaluating the level of work-related stress of seafarers.

However, such objective measurements cannot replace the GHQ12 questionnaire instrument to measure the specific daily problems, such as sleeping problems, but the biomarkers may be used as supplement to the questionnaire measures to be further developed. While the primary objective was to evaluate the well-being of the seafarers during the outbreak of COVID-19 pandemic, the intention is also to create the basis for a permanent monitoring of the seafarer's health and well-being in an international perspective. These studies will serve as the scientific evidence base to assess the effect of the implementation of the
ILO-based International Conventions, the Maritime Labour Convention 2006 for seafarers. And due to the continuing appearance of new health risks a permanent surveillance of the maritime health and safety is needed.

\section{CONCLUSIONS}

A combination of elevated Likert score to the level of "starting problems" for $15-47 \%$ of the sample and more than $50 \%$ of all did not feel safe about the precautions done by the shipping company indicates an urgent need to establish a care-taking programme for the seafarers. A combination of person-focused and organisation-focused approaches has been proposed to be the most promising way for prevention. On the personal level, guidelines of prevention for the crew on board and the crew exchange with test of infection before embarkation of new crew is recommended. Extensive communication to all seafarers during the situation with information of the possibility to disembark and the flights home and the economic situation for them; access to unlimited internet for tele-communication to home, access to Radio-Television and to Radio-Medical and the possibility of getting test on board before they disembark (incubation time) are some of the important requirements besides masks and disinfection remedies available. In some cases, individual crisis consultations with the company psychologist and occupational doctor may be useful, but for the population at large there is no good evidence that programs with individual consultations has any effect on the longer perspective [13]. Some studies available in the literature provide us with indications about the importance of psychological problems (such as depression and suicidal risk), and also show us the difficulty of studying and measuring the problem [11]. In this context, it is very important to carefully evaluate the risk of work-related stress. Our results also show a certain difficulty and uncertainty in framing this kind of problem in the population of seafarers, even in the pandemic period. In light of our results, we could say that seafarers' resistance to stress appears to be remarkable, even in a pandemic period. We can therefore state that further studies on this topic would be necessary also with the aid, as anticipated, of more objective stress measurement systems, such as biological indicators.

On the organisational level, there are detailed guidelines from the IMO/ILO and the National Maritime Authorities on how the companies should be prepared and ready to act adequately.

\section{ACKNOWLEDGEMENTS}

We thank all the seafarers participating in the study and the Terminal Logistic Company "Trieste Marine Terminal SPA" (TO Delta Group), Trieste. 


\section{REFERENCES}

1. Jeżewska M, Leszczyńska I, Jaremin B. Work related stress in seamen. Int Marit Health. 2006; 57(1-4): 66-75.

2. Oldenburg M, Jensen HJ, Latza U, et al. Seafaring stressors aboard merchant and passenger ships. Int J Public Health. 2009; 54(2): 96-105, doi: 10.1007/s00038-009-7067-z, indexed in Pubmed: 19288290.

3. Agterberg G, Passchier J. Stress among seamen. Psychol Rep. 1998; 83(2): 708-710, doi: 10.2466/pr0.1998.83.2.708, indexed in Pubmed: 9819944.

4. Semmer NK. Job stress interventions and the organization of work. Scand J Work Environ Health. 2006; 32(6): 515-527, doi: 10.5271/ sjweh.1056, indexed in Pubmed: 17173207.

5. Lamontagne AD, Keegel T, Louie AM, et al. A systematic review of the job-stress intervention evaluation literature, 1990-2005. Int J Occup Environ Health. 2007; 13(3): 268-280, doi: 10.1179/oeh.2007.13.3.268, indexed in Pubmed: 17915541.

6. Doyle N, MacLachlan M, Fraser A, et al. Resilience and well-being amongst seafarers: cross-sectional study of crew across 51 ships. Int Arch Occup Environ Health. 2016; 89(2): 199-209, doi: 10.1007/ s00420-015-1063-9, indexed in Pubmed: 26062930.
7. Sampson H, Ellis N, Acejo I, et al. Changes in seafarers' health 2011 16: A summary report. SIRC. 2017; 22.

8. Martin C, Newell R. Is the 12-item General Health Questionnaire (GHQ-12) confounded by scoring method in individuals with facial disfigurement? Psychology Health. 2005; 20(5): 651-659, doi: 10.1080/14768320500060061.

9. Lundin A, Hallgren $\mathrm{M}$, Theobald $\mathrm{H}$, et al. Validity of the 12 -item version of the General Health Questionnaire in detecting depression in the general population. Public Health. 2016; 136: 66-74, doi: 10.1016/j. puhe.2016.03.005, indexed in Pubmed: 27040911.

10. Winefield A, Gillespie N, Stough C, et al. Occupational stress in Australian university staff: Results from a national survey. Int J Stress Manag. 2003; 10(1): 51-63, doi: 10.1037/1072-5245.10.1.51.

11. Mellbye A, Carter T. Seafarer's depression and suicide. Int Marit Health. 2017; 68(2): 108-114.

12. Ali N, Nater UM. Salivary alpha-amylase as a biomarker of stress in behavioral medicine. Int J Behav Med. 2020; 27(3): 337-342, doi: 10.1007/s12529-019-09843-x, indexed in Pubmed: 31900867.

13. Jensen 0 , Charalambous G, Flores A, et al. Strategies for prevention of non-communicable diseases in seafarers and fishermen: lessons learned. Int J Community Family Med. 2018; 3(2), doi: 10.15344/2456-3498/2018/142. 